\title{
LOCAL VELOCITY PROFILES MEASURED BY PIV IN A VESSEL AGITATED BY A RUSHTON TURBINE
}

\author{
RADEK ŠulC*, VÍt Pešava, PAVel Ditl \\ Czech Technical University in Prague, Faculty of Mechanical Engineering, Department of Process Engineering, \\ Technická 4, 16607 Prague, Czech Republic \\ * corresponding author: Radek.Sulc@fs.cvut.cz
}

\begin{abstract}
The hydrodynamics and flow field were measured in an agitated vessel using 2-D Time Resolved Particle Image Velocimetry (2-D TR PIV). The experiments were carried out in a fully baffled cylindrical flat bottom vessel $300 \mathrm{~mm}$ in inner diameter. The tank was agitated by a Rushton turbine $100 \mathrm{~mm}$ in diameter. The velocity fields were measured for three impeller rotation speeds: $300 \mathrm{rpm}$, $450 \mathrm{rpm}$ and $600 \mathrm{rpm}$, and the corresponding Reynolds numbers in the range $50000<R e<100000$, which means that fully-developed turbulent flow was reached. In accordance with the theory of mixing, the dimensionless mean and fluctuation velocities in the measured directions were found to be constant and independent of the impeller rotational speed. The velocity profiles were averaged, and were expressed by Chebyshev polynomials of the 1st order. Although the experimentally investigated area was relatively far from the impeller, and it was located in upward flow to the impeller, no state of local isotropy was found. The ratio of the axial rms fluctuation velocity to the radial component was found to be in the range from 0.523 to 0.768 . The axial turbulence intensity was found to be in the range from 0.293 to 0.667 , which corresponds to a high turbulence intensity.
\end{abstract}

KEYwords: mixing, Rushton turbine, Particle Image Velocimetry, flow, velocity profile, mean velocity, fluctuation velocity.

\section{INTRODUCTION}

It is important to know the flow and the flow pattern in an agitated vessel in order to determine many impeller and turbulence characteristics, e.g. impeller pumping capacity, intensity of turbulence, turbulent kinetic energy, convective velocity, and the turbulent energy dissipation rate. The information and data that are obtained can also be used for CFD verification.

Drbohlav et al. 1 1 made an experimental investigation of the velocity field in the stream discharging from a Rushton turbine at Reynolds numbers $R e=146000$ and $R e=166000$. They described the axial profiles of the mean velocity components in this region using a phenomenological three-parameter model based on a tangential cylindrical jet, proposed by 2 . Obeid et al. [3] used the proposed model to describe the velocity field in the discharged flow produced by various types of turbine impellers.

The flow in a mechanically agitated vessel should be divided into several regions where the flow behaviour is quite different. Forrt et al. 4 divided the flow in a vessel agitated by a Rushton turbine into the following regions:

(1.) region $\mathrm{O}$, in which the stream discharges from the impeller;

(2.) region A, close to the wall, in which the flow direction changes from radial into axial;

(3.) region $\mathrm{B}$, which contains the predominantly ascending and descending sections of flow along the vessel wall;
(4.) region $\mathrm{C}$, in which the flow direction changes from axial to radial at the vessel bottom or at the liquid surface;

(5.) region $\mathrm{D}$, which contains the prevailing radial flow at the vessel bottom or at the liquid surface;

(6.) region $\mathrm{E}$, in which the flow at the bottom or at the surface turns into the direction of the vessel axis;

(7.) region $\mathrm{F}$, which contains the predominantly ascending or descending flow along the vessel axis towards the impeller;

(8.) region $\mathrm{G}$, in which the streamline pattern is stagnant and unstable, where neither of the mean velocity components is significant.

The flow pattern characterized by the mean velocity components is described by the proposed theoretical model based on the Stokes stream function.

Although the flow discharging from an impeller has been investigated by many authors, the regions outside the impeller region have not been treated with the same level of interest ([5]). The aim of this work is to study scaling of the velocity field outside the impeller region in a vessel mechanically agitated by a Rushton turbine in a fully turbulent region at a high Reynolds number in the range of $50000<R e<100000$. The hydrodynamics and the flow field were measured in an agitated vessel using Time Resolved Particle Image Velocimetry (TR PIV). The radial profiles of the mean and fluctuation velocities are expressed in terms of Chebyshev polynomials. 


\section{Theoretical BaCkground}

\subsection{INSPECTION ANALYSIS OF FLOW IN AN AGITATED VESSEL}

The flow of a Newtonian fluid in an agitated vessel has been described by the Navier - Stokes equation:

$$
\varrho\left(\frac{\partial \vec{U}}{\partial t}+\vec{U} \cdot \nabla \vec{U}\right)=-\nabla p+\mu \nabla^{2} \vec{U}+\varrho \vec{g}
$$

This equation can be rewritten into dimensionless form, as follows (e.g. [6]):

$$
\frac{\partial \vec{U}^{*}}{\partial t^{*}}+\vec{U}^{*} \cdot \nabla^{*} \vec{U}^{*}=-\nabla^{*} p^{*}+\frac{1}{R e} \nabla^{* 2} \vec{U}^{*}+\frac{1}{F r} \vec{n}^{*},
$$

where the dimensionless properties are defined as follows:

- dimensionless instantaneous velocity $\vec{U}^{*}=\frac{\vec{U}}{N D}$;

- dimensionless instantaneous pressure $p^{*}=\frac{p}{\varrho N^{2} D^{2}}$;

- dimensionless space gradient $\nabla^{*}=\frac{\nabla}{D}$;

- Reynolds number $R e=\frac{N D^{2}}{\nu}$;

- Froude number $\mathrm{Fr}=\frac{N^{2} D}{g}$;

and where $\vec{n}$ is a unity vector.

Similarly, the equation of continuity for stationary flow of a non-compressible fluid given as

$$
\nabla \cdot \vec{U}=0
$$

can be rewritten into the dimensionless form:

$$
\nabla^{*} \cdot \vec{U}^{*}=0 .
$$

The following relations can be obtained for dimensionless velocity components and dimensionless pressure, respectively, by inspection analysis of Eqs. (2) and (4), as follows:

$$
\begin{aligned}
\vec{U}^{*} & =f_{1}\left(\vec{x}^{*}, t^{*}, R e, F r\right), \\
p^{*} & =f_{2}\left(\vec{x}^{*}, t^{*}, R e, F r\right),
\end{aligned}
$$

where $\vec{x}^{*}$ is a dimensionless location vector.

For stationary flow with a periodic character, the velocity time dependence can be eliminated by substituting the velocity and pressure by time-averaged properties. For highly turbulent flow in a baffled vessel, the viscous and gravitational forces can be neglected and finally the time-averaged dimensionless velocity components and the pressure are independent of the Reynolds number and the Froude number, and depend on location only:

$$
\overline{U_{i}^{*}}=f_{1}\left(\vec{x}^{*}\right), \quad p^{*}=f_{2}\left(\vec{x}^{*}\right),
$$

Reynolds decomposition of the instantaneous velocity components has been applied for the velocity profiles studied in this work.

\subsection{MEAN AND FLUCTUATION VELOCITY}

Using PIV, the instantaneous velocity data set $U_{i}\left(t_{j}\right)$ in the $i$ th direction for $j=1,2, \ldots, N_{R}$ at observation times $t_{j}$ with an equidistant time step $\Delta t_{S}$ (i.e., $\Delta t_{S}=$ $t_{j+1}-t_{j}$ ) was obtained in a given location. Assuming the so-called ergodic hypothesis, the time-averaged mean velocity $\overline{U_{i}}$ was determined as the average value of velocity data set $U_{i}\left(t_{j}\right)$ :

$$
\overline{U_{i}}=\frac{1}{N_{R}} \sum_{j=1}^{N_{R}} U\left(t_{j}\right)
$$

where $\overline{U_{i}}$ is mean velocity in the $i$ th direction, $U_{i}(t j)$ is instantaneous velocity in the $i$ th direction at observation time $t_{j}$, and $N_{R}$ is the number of data items in the velocity data set.

Consequently, the fluctuation velocity in the $i$ th direction $u_{i}\left(t_{j}\right)$ at observation time $t_{j}$ is obtained by decomposition of the instantaneous velocity:

$$
u_{i}\left(t_{j}\right)=U_{i}\left(t_{j}\right)-\overline{U_{i}} \quad \text { for } \quad j=1,2, \cdots N_{R},
$$

where $u_{i}\left(t_{j}\right)$ is the fluctuation velocity in the $i$ th direction at observation time $t_{i}, \overline{U_{i}}$ is mean velocity in the $i$ th direction, $U_{i}\left(t_{j}\right)$ is instantaneous velocity in the $i$ th direction at observation time $t_{j}$.

The root mean squared fluctuation velocity is determined as follows:

$$
\overline{u_{i}}=\left(\frac{1}{N_{R}} \sum_{j=1}^{N_{R}} u_{i}\left(t_{j}\right)^{2}\right)^{1 / 2},
$$

where $\overline{u_{i}}$ is the root mean squared fluctuation velocity, and $u\left(t_{j}\right)$ is the fluctuation velocity at observation time $t_{j}$.

\section{EXPERIMENTAL}

The hydrodynamics and the flow field were measured in an agitated vessel using Time Resolved Particle Image Velocimetry (TR PIV). The experiments were carried out in a fully baffled cylindrical flat bottom vessel $300 \mathrm{~mm}$ in inner diameter [7]. The tank was agitated by a Rushton turbine $100 \mathrm{~mm}$ in diameter, i.e., the dimensionless impeller diameter $D / T$ was $1 / 3$. The dimensionless impeller clearance $C / D$ taken from the lower impeller edge was 0.75 . The tank was filled with degassed distilled water, and the liquid height was $300 \mathrm{~mm}$, i.e., the dimensionless liquid height $H / T$ was 1 . The dimensionless baffle width $B / T$ was $1 / 10$. To prevent air suction, the vessel was covered by a lid. Velocity fields were measured for three impeller rotation speeds: 300, 450 and $600 \mathrm{rpm}$, at which fully developed turbulent flow was reached. Distilled water at a temperature of $23^{\circ} \mathrm{C}$ (density $\varrho=997.4 \mathrm{~kg} \mathrm{~m}^{-3}$, dynamic viscosity $\mu=0.9321 \mathrm{mPas}$ ) was used as the agitated liquid.

The time resolved LITRON LDY 304 2D-PIV system (Dantec Dynamics (Denmark)) consists of a 
Neodyme-YLF laser (light wave length $532 \mathrm{~nm}$, impulse energy $2 \times 30 \mathrm{MJ}$ ), a SpeedSence 611 high speed PIV-regime camera (resolution $1280 \times 1024$ pixels) with a Sigma MacroDg objective equipped with an optical filter with wave length $570 \mathrm{~nm}$. Rhodamine B fluorescent particles of mean diameter $11.95 \pm 0.25 \mu \mathrm{m}$ were used as seeding particles. The fluorescent particles lit by $532 \mathrm{~nm}$ light emit $570 \mathrm{~nm}$ light. In this way, non-seeding particles such as impurities and bubbles are separated and are not recorded. The operating frame rate was $1 \mathrm{kHz}$ (1000 vector fields per second), i.e., the sampling time $\Delta t_{s}$ was $1 \mathrm{~ms}$.

The measured vertical plane was located in the center of the vessel and in the middle of the baffles. The plane was illuminated by a laser sheet $0.7 \mathrm{~mm}$ in thickness. The investigated area was $43 \times 27 \mathrm{~mm}$. The position of the right top apex $\mathrm{E}\left[r_{E} ; z_{E}\right]$ was $[10 ; 55]$, i.e., $r^{*}=2 r / T=20 / 300$ and $z^{*}=z / T=55 / 300$, i.e., the right top edge was located $20 \mathrm{~mm}$ below the impeller paddle edge and $10 \mathrm{~mm}$ from the impeller axis. The scheme of the experimental apparatus and the investigated area are depicted in Fig. 1. The camera was positioned orthogonally to the laser sheet. The experiments were conducted in the framework of cooperation with Dr M. Kotek (Technical University Liberec) and Dr B. Kysela (Institute of Hydrodynamics, Czech Academy of Sciences). The velocity profiles in four horizontal planes located in the investigated area in the positions $z^{*}=0.1114,0.1294,0.1474$ and 0.1654 are presented in this paper in the dimensionless radius range $r^{*}=\langle 0.0702 \div 0.3509\rangle$. The investigated area corresponds to region $\mathrm{F}$ according to the classification given by Fořt et al. (1982). The ensemble averaged velocity field method can be used due to the axisymmetric character of the flow in this region. For all experiments, 5000 images were taken at a sampling interval of $0.001 \mathrm{~s}$, i.e., the total record time length was $5 \mathrm{~s}$. Unfortunately, a recording time of only $3.865 \mathrm{~s}$ was available for the $300 \mathrm{rpm}$ measurement, due to damage to the storage disk.

\section{ExPERIMENTAL DATA EVALUATION}

According to the inspection analysis, the dimensionless velocities normalized by the product of impeller speed $N$ and impeller diameter $D$ should be independent of the Reynolds number. For a single impeller size and a single liquid, this dimensionless velocity should be independent of the impeller rotational speed.

The effect of impeller rotational speed on dimensionless velocities was tested by hypothesis testing 8 . The statistical method for hypothesis testing can estimate whether the differences between the predicted parameter values (e.g., predicted by some proposed theory) and the parameter values evaluated from the measured data are negligible. In this case, we assumed dependence of the tested parameter on the impeller rotational speed, described by the simple power law parameter $=B N^{\beta}$, and the difference between predicted exponent $\beta_{\text {pred }}$ and evaluated exponent $\beta_{\text {calc }}$
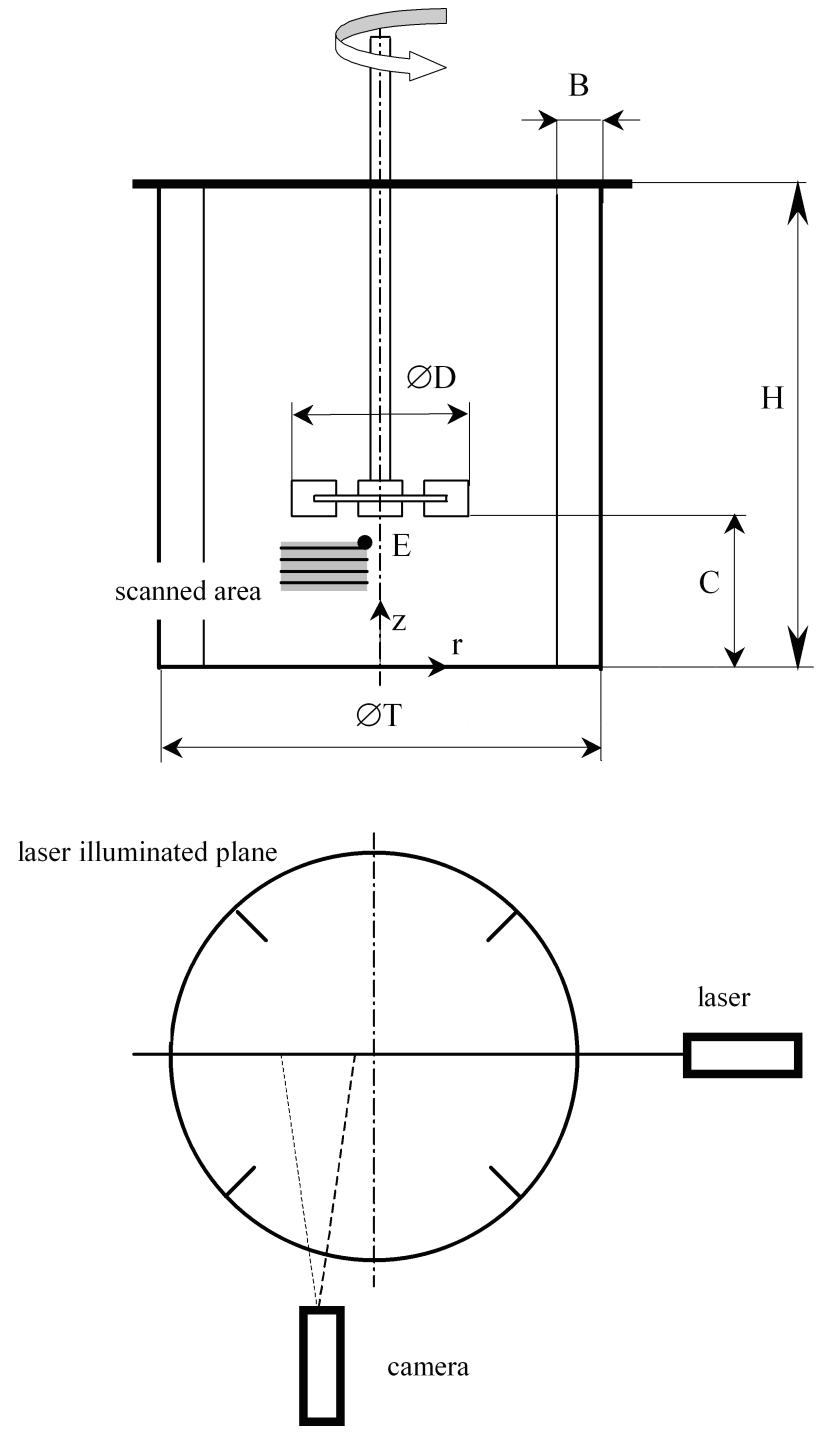

Figure 1. Scheme of the experimental apparatus and the investigated area.

was tested. The hypothesis test characteristics are given as $t=\left(\beta_{\text {calc }}-\beta_{\text {pred }}\right) / s_{\beta}$ where $s_{\beta}$ is the standard error of parameter $\beta_{\text {calc }}$. If the calculated $|t|$ value is less than the critical value of the $t$-distribution for $m-2$ degrees of freedom and significance level $\alpha$, the difference between $\beta_{\text {calc }}$ and $\beta_{\text {pred }}$ is statistically negligible (statisticians state: "the hypothesis cannot be rejected"). In our case, the independence of dimensionless velocities from the impeller speed was tested as the hypothesis, i.e., parameter $=B N^{0}=$ const., i.e., $\beta_{\text {pred }}=0$. The $t$-distribution coefficient $t_{m-2, \alpha}$ for three impeller rotational speeds and significance level $\alpha=0.05$ is 12.706 . Hypothesis testing was performed for each point in the investigated profiles. The hypothesis test results are presented for each profile in Table 1 by the percentage of points in which the above-formulated hypothesis parameter $=$ const. is satisfied, and by the percentage of points in which the hypothesis parameter $=$ const. cannot be accepted. For illustration, the average calculated $|t|$ values are also presented here. 


\begin{tabular}{|c|c|c|c|c|}
\hline \multicolumn{5}{|c|}{$\begin{array}{c}\text { Hypothesis: parameter }=B N^{0} \\
\text { Percentage; } t \text {-characteristics }|t|\end{array}$} \\
\hline Parameter & $\overline{U_{\mathrm{r}}} /(N D)$ & $\overline{u_{\mathrm{r}}} /(N D)$ & $\overline{U_{\mathrm{ax}}} /(N D)$ & $\overline{u_{\mathrm{ax}}} /(N D)$ \\
\hline \multicolumn{5}{|c|}{ Profile $z^{*}=0.1114$} \\
\hline $\begin{array}{l}\text { acceptable } \\
\text { not acceptable }\end{array}$ & $\begin{array}{l}92.4 \% ; 4.1 \\
7.6 \% ; 46.7\end{array}$ & $\begin{array}{c}100 \% ; 0.7 \\
0 \%\end{array}$ & $\begin{array}{c}100 \% ; 3.4 \\
0 \%\end{array}$ & $\begin{array}{c}100 \% ; 0.9 \\
0 \%\end{array}$ \\
\hline \multicolumn{5}{|c|}{ Profile $z^{*}=0.1294$} \\
\hline $\begin{array}{l}\text { acceptable } \\
\text { not acceptable }\end{array}$ & $\begin{array}{l}98.7 \% ; 0.76 \\
1.3 \% ; 185\end{array}$ & $\begin{array}{c}100 \% ; 0.6 \\
0 \%\end{array}$ & $\begin{array}{l}95 \% ; 2.9 \\
5 \% ; 57\end{array}$ & $\begin{array}{l}96.2 \% ; 1.2 \\
3.8 \% ; 47.7\end{array}$ \\
\hline \multicolumn{5}{|c|}{ Profile $z^{*}=0.1474$} \\
\hline $\begin{array}{l}\text { acceptable } \\
\text { not acceptable }\end{array}$ & $\begin{array}{l}100 \% ; 0.9 \\
0 \%\end{array}$ & $\begin{array}{l}100 \% ; 0.6 \\
0 \%\end{array}$ & $\begin{array}{l}92.4 \% ; 4.1 \\
7.6 \% ; 21.5\end{array}$ & $\begin{array}{l}93.7 \% ; 1.1 \\
6.3 \% ; 22.3 \\
\end{array}$ \\
\hline \multicolumn{5}{|c|}{ Profile $z^{*}=0.1654$} \\
\hline $\begin{array}{l}\text { acceptable } \\
\text { not acceptable }\end{array}$ & $\begin{array}{l}95 \% ; 2.4 \\
5 \% ; 28.1\end{array}$ & $\begin{array}{c}100 \% ; 0.73 \\
0 \%\end{array}$ & $\begin{array}{l}86.1 \% ; 2.81 \\
13.9 \% ; 51.3\end{array}$ & $\begin{array}{c}97.5 \% ; 1.44 \\
2.5 \% ; 18.1\end{array}$ \\
\hline
\end{tabular}

TABLE 1. Dimensionless velocities - effect of impeller speed.

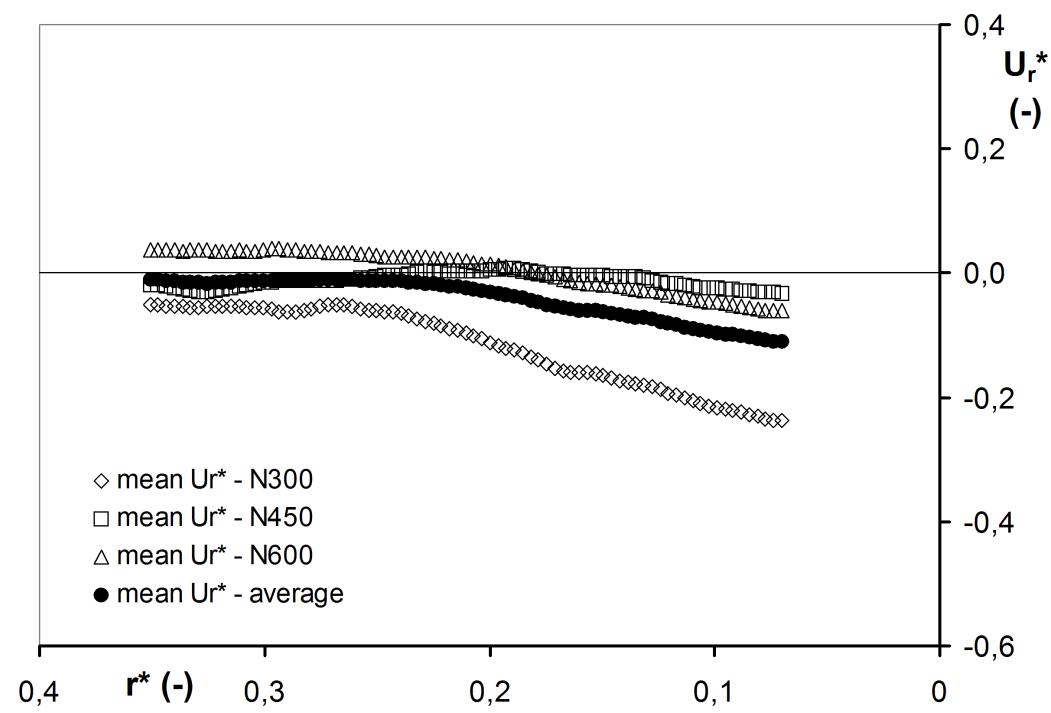

FigurE 2. Dimensionless radial mean velocity profile - effect of impeller speed; $z^{*}=0.1474$.

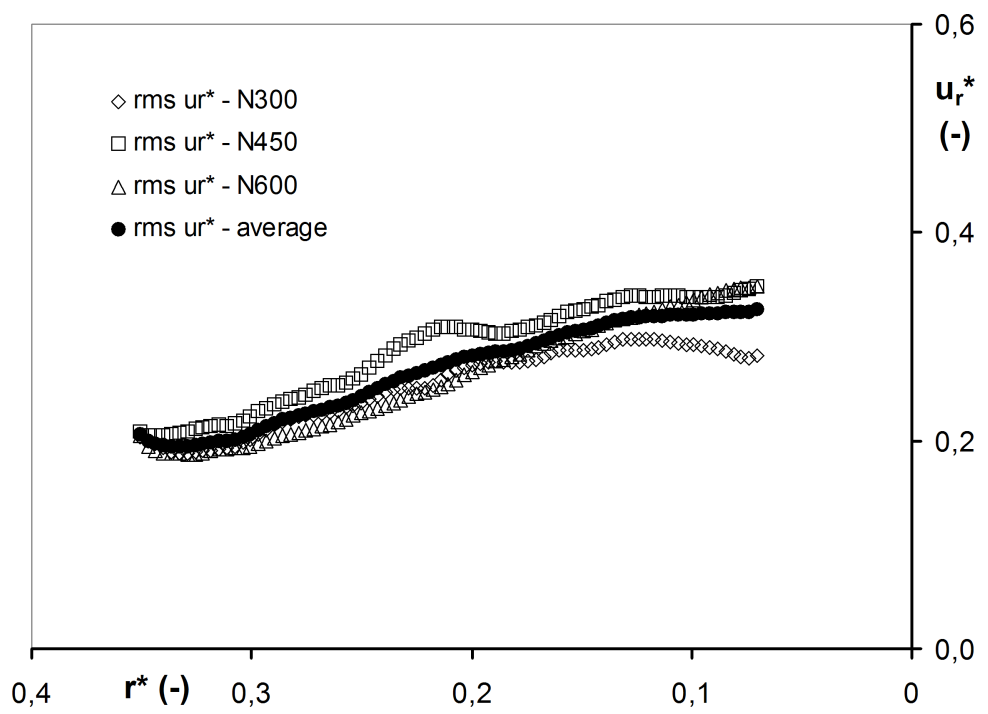

FIGURE 3. Dimensionless radial fluctuation velocity profile - effect of impeller speed; $z^{*}=0.1474$. 


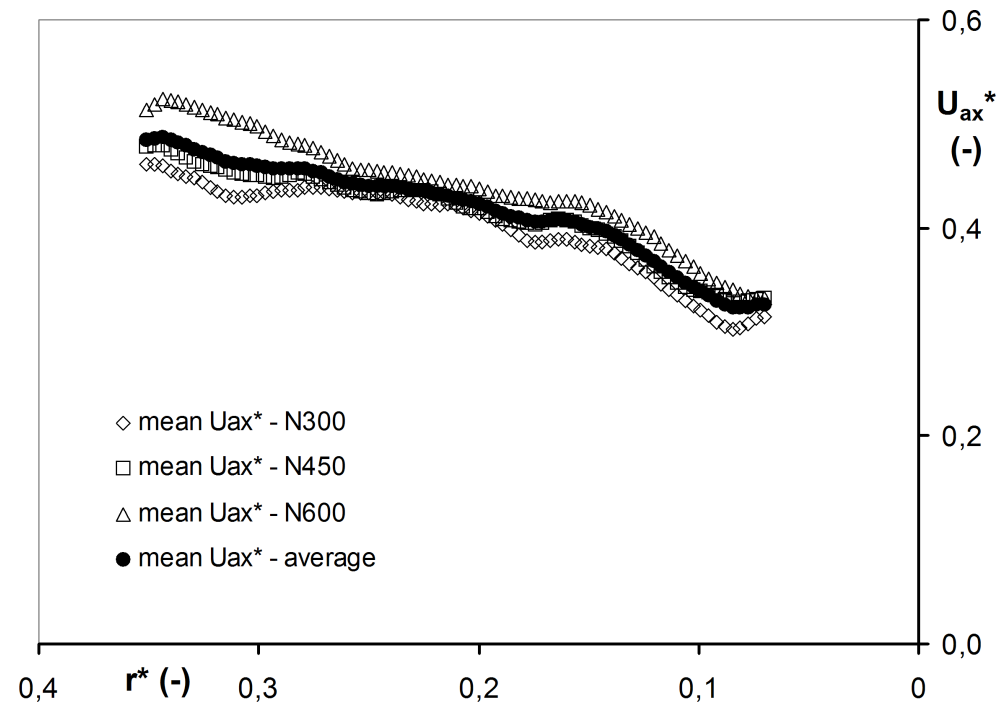

Figure 4. Dimensionless axial mean velocity profile - effect of impeller speed; $z^{*}=0.1474$.

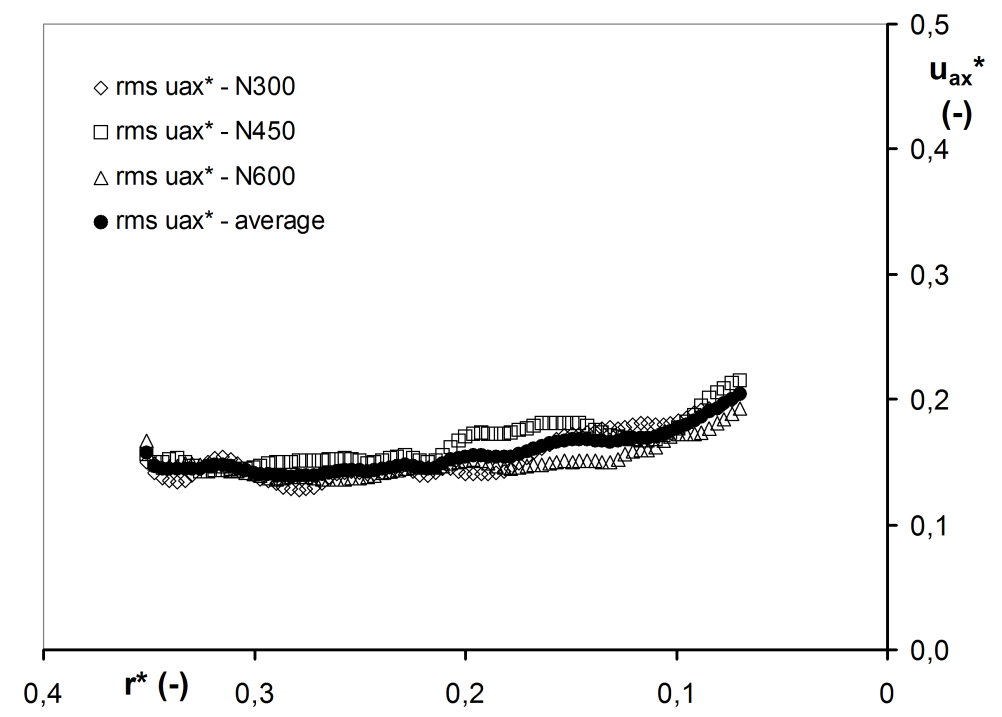

FIGURE 5. Dimensionless axial fluctuation velocity profile - effect of impeller speed; $z^{*}=0.1474$.

For illustration, the profiles of the dimensionless velocities for three impeller speeds and their average are presented in Figures 2 5 for the line $z^{*}=0.1474$. The dimensionless radial mean velocities were found to be close to zero. As shown in Fig. 2, some velocity values are positive, while other velocity values are negative. These findings correspond to characteristics of the given zone, according to Fořt et al. (1982). This region contains predominantly ascending flow along the vessel axis towards the impeller. The dimensionless axial mean velocity was found to be in the range from 0.323 to 0.488 . These values are higher than the dimensionless values for the radial mean velocity, as expected for this region. The tested hypothesis can be accepted in almost all profile points.

The dimensionless radial rms fluctuation velocities were found to be in the range from 0.194 to 0.326 . The tested hypothesis can be accepted in all profile points, as is signalized by the very low calculated $|t|$ values. The dimensionless axial rms fluctuation velocities were found to be in the range from 0.139 to 0.204 . The tested hypothesis can be accepted in the majority of profile points as is again signalized by the low calculated $|t|$ values.

Because the selected position is relatively far from the impeller and outside the impeller discharge flow, we expected the local isotropy state defined on the length-scale level corresponding to integral length scale to be an equality of the fluctuation velocity components. However, this expectation was not confirmed. The ratio of the axial rms fluctuation velocity to the radial component was found to be in the range from 0.523 to 0.768 .

On the basis of the results of this hypothesis test, we assume that all dimensionless velocities can be statistically taken as constant and independent of the impeller rotational speed. The velocity profiles were averaged, and were expressed by the polynomial approximation written in Chebyshev form. 


\begin{tabular}{|c|c|c|c|c|c|c|c|}
\hline Profile & $a_{0} \times 10^{+2}$ & $a_{1} \times 10^{+2}$ & $a_{2} \times 10^{+2}$ & $a_{3} \times 10^{+3}$ & $a_{4} \times 10^{+3}$ & $I_{y x}^{\dagger}$ & $\delta_{\mathrm{r} \text { ave }} / \delta_{\mathrm{r} \max }^{\ddagger}$ \\
\hline \multicolumn{8}{|c|}{ Radial mean velocity $\overline{U_{\mathrm{r}}} /(N D)$} \\
\hline$z^{*}=0.1114$ & -0.8872 & 8.407 & -2.716 & -2.484 & 4.457 & 0.9988 & $30.7 / 1459$ \\
\hline$z^{*}=0.1294$ & -2.893 & 6.289 & -2.276 & -2.649 & 4.652 & 0.9987 & $30.8 / 1249$ \\
\hline$z^{*}=0.1474$ & -4.727 & 5.097 & -1.772 & -3.677 & 3.809 & 0.998 & $6.5 / 22$ \\
\hline$z^{*}=0.1654$ & -6.457 & 3.907 & -1.455 & -4.148 & 3.322 & 0.9957 & $3.8 / 10.5$ \\
\hline \multicolumn{8}{|c|}{ Axial mean velocity $\overline{U_{\mathrm{ax}}} /(N D)$} \\
\hline$z^{*}=0.1114$ & 36.37 & 7.362 & 0.7714 & 3.053 & 4.342 & 0.9967 & $0.82 / 2.2$ \\
\hline$z^{*}=0.1294$ & 39.74 & 7.974 & -0.6153 & 8.866 & 0.1507 & 0.9975 & $0.7 / 1.7$ \\
\hline$z^{*}=0.1474$ & 41.36 & 8.17 & -1.387 & 7.645 & 2.016 & 0.9953 & $0.9 / 4.6$ \\
\hline$z^{*}=0.1654$ & 42.31 & 7.801 & -2.142 & 8.041 & 7.179 & 0.9975 & $0.6 / 3.2$ \\
\hline \multicolumn{8}{|c|}{ Radial rms fluctuation velocity $\overline{u_{\mathrm{r}}} /(N D)$} \\
\hline$z^{*}=0.1114$ & 27.84 & -8.426 & 1.025 & 8.843 & 3.06 & 0.9983 & $1 / 1.8$ \\
\hline$z^{*}=0.1294$ & 27.08 & -7.825 & 0.1065 & 8.521 & 5.46 & 0.9987 & $0.73 / 2.6$ \\
\hline$z^{*}=0.1474$ & 26.44 & -7.295 & -0.5566 & 8.669 & 3.414 & 0.9986 & $0.8 / 3.8$ \\
\hline$z^{*}=0.1654$ & 25.5 & -6.929 & -0.3675 & 7.561 & 6.272 & 0.9969 & $1.1 / 2.8$ \\
\hline \multicolumn{8}{|c|}{ Axial rms fluctuation velocity $\overline{u_{\mathrm{ax}}} /(N D)$} \\
\hline$z^{*}=0.1114$ & 14.65 & -1.313 & 1.212 & 0.2547 & 1.802 & 0.977 & $1.14 / 4.7$ \\
\hline$z^{*}=0.1294$ & 15.29 & -2.063 & 1.151 & 1.144 & 1.028 & 0.9759 & $1.8 / 4.1$ \\
\hline$z^{*}=0.1474$ & 16.07 & -2.347 & 1.317 & 0.2177 & 2.836 & 0.9828 & $1.6 / 4.6$ \\
\hline$z^{*}=0.1654$ & 16.78 & -2.84 & 1.746 & -3.173 & 1.911 & 0.994 & $0.91 / 6.5$ \\
\hline
\end{tabular}

$\dagger$ Correlation index. $\ddagger$ Relative error of velocity: average/maximum absolute value.

TABLE 2. Profiles of dimensionless velocity components - coefficients of polynomial approximation in Chebyshev form.

\subsection{The profile as a FunCtion of the DIMENSIONLESS RADIUS}

The velocity profiles were described as a function of dimensionless radius $r^{*}$ in the range $r^{*} \in\left\langle r_{\text {lower }}^{*} ; r_{\text {upper }}^{*}\right\rangle$ using Chebyshev polynomials of the 1 st order (see [9], based on the original work of Chebyshev [10]), as follows:

$$
\text { parameter }=\sum_{k=0}^{4} a_{k} T_{k}\left(x_{\mathrm{CH}}\right),
$$

where $a_{k}$ are coefficients of polynomial approximation in Chebyshev form, consisting of four terms, $x_{\mathrm{CH}}$ is the Chebyshev polynomial variable, and $T_{k}\left(x_{\mathrm{CH}}\right)$ are Chebyshev polynomials, defined as follows:

$$
\begin{aligned}
& T_{0}\left(x_{\mathrm{CH}}\right)=1, \\
& T_{1}\left(x_{\mathrm{CH}}\right)=x_{\mathrm{CH}}, \\
& T_{2}\left(x_{\mathrm{CH}}\right)=2 x_{\mathrm{CH}}^{2}-1, \\
& T_{3}\left(x_{\mathrm{CH}}\right)=4 x_{\mathrm{CH}}^{3}-3 x_{\mathrm{CH}}, \\
& T_{4}\left(x_{\mathrm{CH}}\right)=8 x_{\mathrm{CH}}^{4}-8 x_{\mathrm{CH}}^{2}+1 .
\end{aligned}
$$

The four terms of polynomial approximation were found to be sufficient for a quality description of the velocity profiles in this region. The Chebyshev polynomial variable $x_{\mathrm{CH}}$ was calculated as follows:

$$
x_{\mathrm{CH}}=\frac{2 r^{*}-\left(r_{\text {lower }}^{*}+r_{\mathrm{upper}}^{*}\right)}{r_{\mathrm{upper}}^{*}-r_{\text {lower }}^{*}},
$$

where $r^{*}$ is dimensionless radius in a given point defined as the ratio of radius $r$ in a given point and tank radius $T / 2, r_{\text {lower }}^{*}$ and $r_{\text {upper }}^{*}$ are the lower and upper limit values of the dimensionless radius. The evaluated parameters of the Chebyshev polynomials are presented in Table 2. A comparison of the averaged velocity profiles and the regression polynomials is presented in Figures 69 for all four horizontal positions. Extremely high relative error values obtained for the dimensionless radial mean velocity were observed for values close to zero.

For faster calculation of the velocity in a given point, Eq. (11) can be rewritten into the following form:

$$
\text { parameter }=b_{0}+b_{1} x_{\mathrm{CH}}+b_{2} x_{\mathrm{CH}}^{2}+b_{3} x_{\mathrm{CH}}^{3}+b_{4} x_{\mathrm{CH}}^{4} \text {, }
$$

where

$$
\begin{aligned}
& b_{0}=a_{0}-a_{2}+a_{4}, \\
& b_{1}=a_{1}-3 a_{3}, \\
& b_{2}=2 a_{2}-8 a_{4}, \\
& b_{3}=4 a_{3}, \\
& b_{4}=8 a_{4} .
\end{aligned}
$$

\subsection{Intensity OF TURBULENCE}

The axial turbulence intensity was calculated as follows:

$$
\mathrm{TI}_{\mathrm{ax}}=\overline{U_{\mathrm{ax}}} / \overline{u_{\mathrm{ax}}},
$$




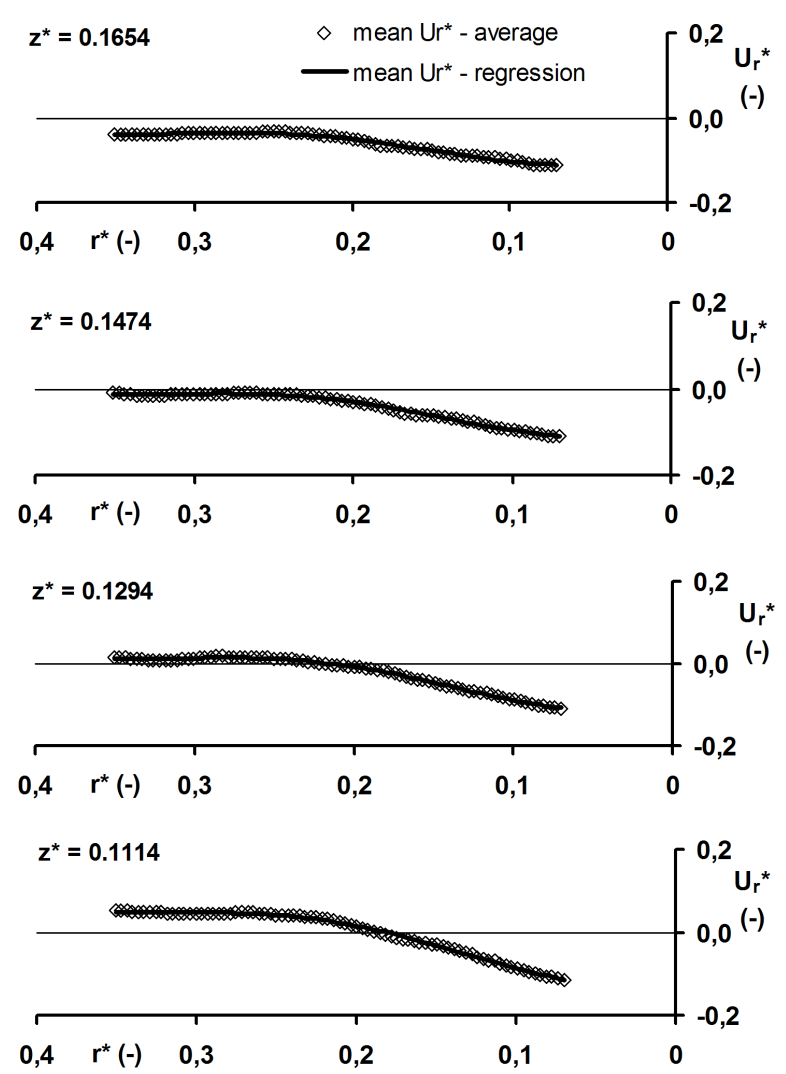

Figure 6. Dimensionless radial mean velocity profile $\overline{U_{\mathrm{r}}} /(N D)=f\left(r^{*}\right)$.
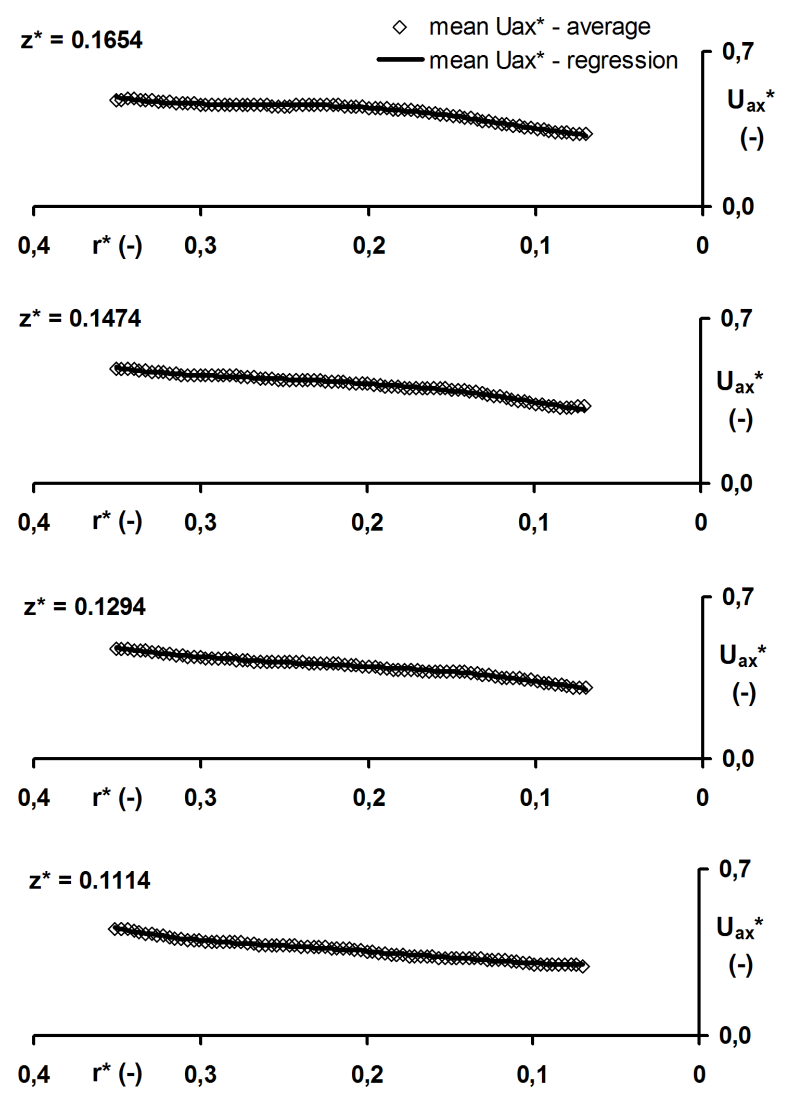

Figure 8. Dimensionless axial mean velocity profile $\overline{u_{\mathrm{r}}} /(N D)=f\left(r^{*}\right)$.
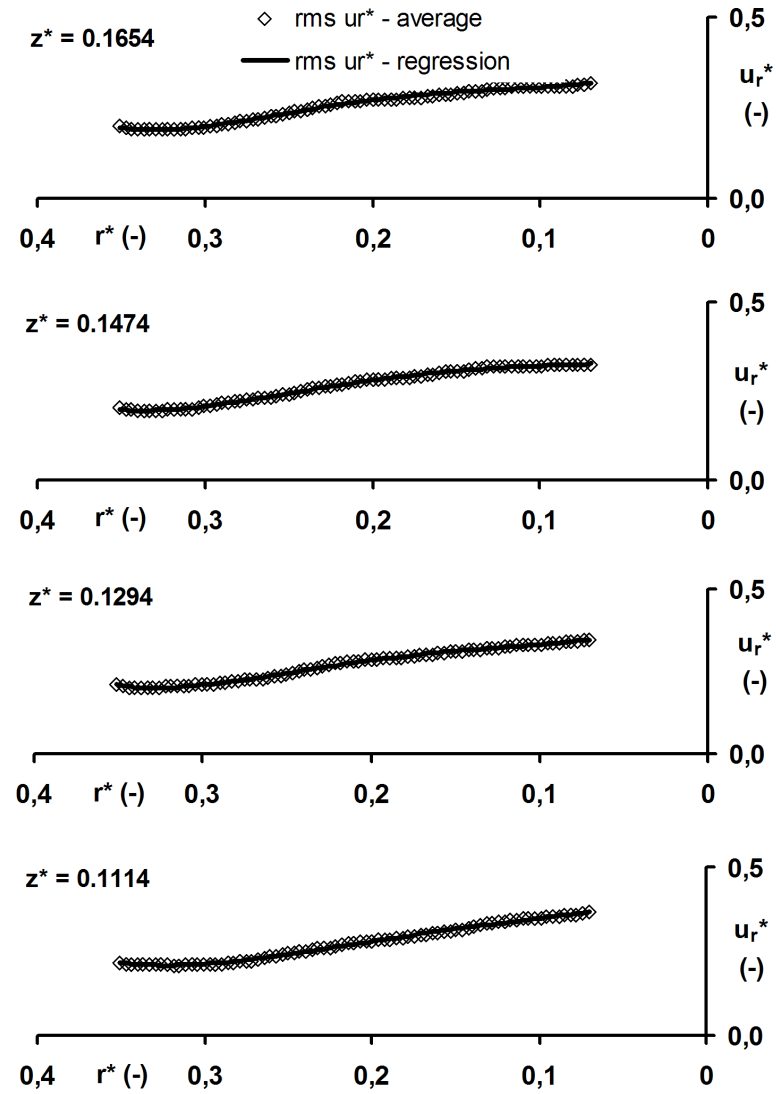

FIGURE 7. Dimensionless radial fluctuation velocity profile $\overline{U_{\mathrm{ax}}} /(N D)=f\left(r^{*}\right)$.
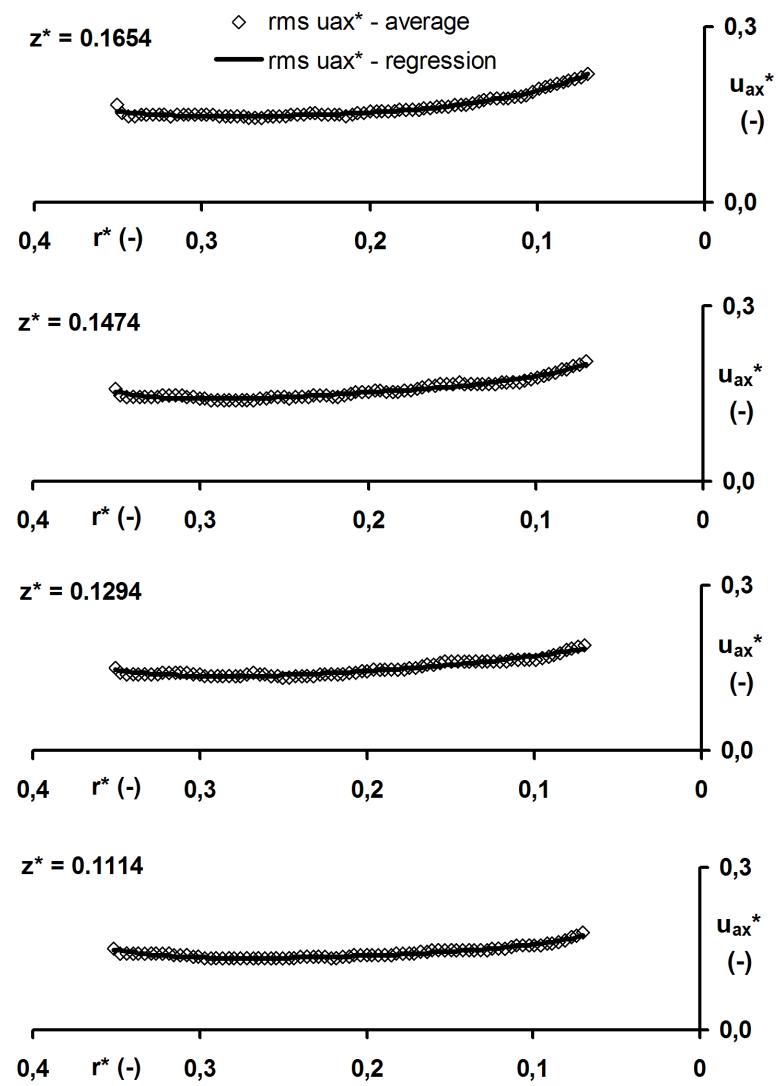

FIgURE 9. Dimensionless axial fluctuation velocity profile $\overline{u_{\mathrm{ax}}} /(N D)=f\left(r^{*}\right)$. 


\begin{tabular}{lcccc}
\hline \multicolumn{5}{c}{$\begin{array}{c}\text { Hypothesis: parameter }=B N^{0} \\
\text { Percentage; } t \text {-characteristics }|t|\end{array}$} \\
\hline Parameter & \multicolumn{4}{c}{ Profile } \\
\cline { 2 - 5 } & $z^{*}=0.1114$ & $z^{*}=0.1294$ & $z^{*}=0.1474$ & $z^{*}=0.1654$ \\
\hline acceptable & $96.2 \% ; 1.91$ & $100 \% ; 1.2$ & $92.4 \% ; 1.64$ & $93.7 \% ; 1.6$ \\
not acceptable & $3.8 \% ; 207$ & $0.00 \%$ & $7.6 \% ; 183$ & $6.3 \% ; 28.1$ \\
\hline
\end{tabular}

TABLE 3. Axial turbulence intensity - effect of impeller speed.

\begin{tabular}{llllllll}
\hline Profile & $a_{0} \times 10^{+2}$ & $a_{1} \times 10^{+2}$ & $a_{2} \times 10^{+2}$ & $a_{3} \times 10^{+3}$ & $a_{4} \times 10^{+3}$ & $I_{y x}^{\dagger}$ & $\delta_{\mathrm{rave}} / \delta_{\mathrm{r} \text { max }}^{\ddagger}$ \\
\hline & \multicolumn{7}{c}{$\mathrm{TI}_{\mathrm{ax}}$} \\
\cline { 2 - 8 }$z^{*}=0.1114$ & 41.64 & -12.34 & 3.817 & -4.749 & 1.637 & 0.9928 & $1.8 / 5.3$ \\
$z^{*}=0.1294$ & 40.06 & -13.94 & 5.261 & -12.62 & 6.243 & 0.9933 & $2.2 / 4.4$ \\
$z^{*}=0.1474$ & 40.49 & -14.58 & 6.237 & -14.92 & 7.515 & 0.9968 & $1.7 / 5.4$ \\
$z^{*}=0.1654$ & 41.37 & -15.59 & 7.88 & -24.23 & 1.472 & 0.9981 & $1.2 / 10.1$ \\
\hline Area & 40.89 & -14.11 & 5.799 & -14.13 & 4.217 & 0.9979 & $1.3 / 4.6$ \\
\hline
\end{tabular}

$\dagger$ Correlation index. $\$$ Relative error of velocity: average/maximum absolute value.

TABLE 4. Profiles of axial turbulence intensity - coefficients of polynomial approximation in Chebyshev form.

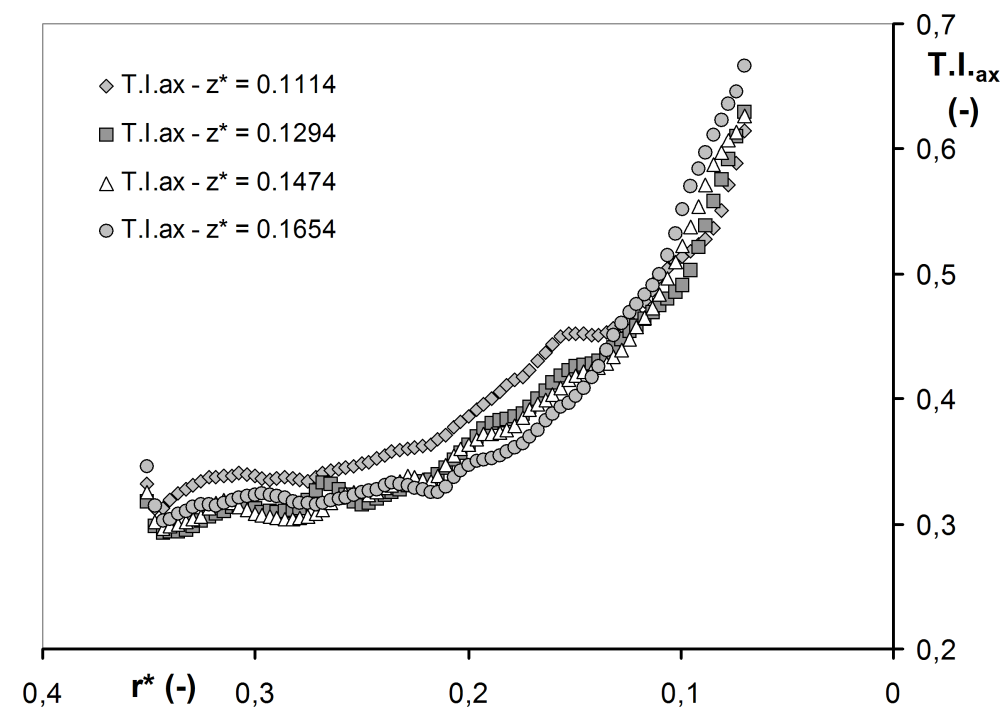

Figure 10. Axial turbulence intensity profile $\mathrm{TI}_{\mathrm{ax}}=f\left(r^{*}\right)$.

where $\overline{u_{\mathrm{ax}}}$ is axial rms fluctuation velocity, and $\overline{U_{\mathrm{ax}}}$ is axial mean velocity. For dimensionless velocities independent of the impeller rotational speed, the turbulence intensity should also be independent from the impeller rotational speed. The independence of dimensionless velocities from impeller speed was again tested by hypothesis testing. The $t$-distribution coefficient $t_{m-2, \alpha}$ for three impeller rotational speeds and significance level $\alpha=0.05$ is 12.706 . Hypothesis testing was performed for each point in the investigated profiles. The hypothesis test results for each profile are presented in Table 3. The tested hypothesis can be accepted in almost all profile points, as is again signalized by the low calculated $|t|$ values.

On the basis of these hypothesis test results, we assume that the axial turbulence intensity can be sta- tistically taken as constant and independent of the impeller rotational speed, as expected. The radial profiles of the axial turbulence intensity were averaged, and were expressed by the polynomial approximation in Chebyshev form. The evaluated coefficients are presented in Table 4. The radial profiles are presented in Fig. 10 for given horizontal positions. As is shown, the calculated values are in the range from 0.293 to 0.667. These values correspond to high turbulence intensity. As expected, the highest turbulence intensity was found close to the impeller axis in the ascending flow core. The calculated axial turbulence intensity values were found to be approximately the same in each horizontal profile, see Fig. 10. The effect of the dimensionless profile height on the turbulence intensity was therefore tested by hypothesis testing for each 
point in the investigated profiles. The t-distribution coefficient $t_{m-2, \alpha}$ for three impeller rotational speeds and significance level $\alpha=0.05$ is 4.3027 . The percentage of points in which the hypothesis $\mathrm{TI}_{\mathrm{ax}}=$ const is satisfied was found to be $73.4 \%$, and the average calculated $|t|$ value was 1.6. The percentage of points in which the hypothesis $\mathrm{TI}_{\mathrm{ax}}=$ const cannot be accepted was found to be $26.6 \%$, and the average calculated $|t|$ value was 8.41 .

On the basis of this hypothesis test result, we assume that the axial turbulence intensity can be statistically taken as constant and independent from the dimensionless profile height in the investigated area. The radial profiles in four horizontal planes were averaged and were expressed by the polynomial approximation in Chebyshev form. The evaluated coefficients denoted as "area" are presented in Table 4

\section{Conclusions}

The following results have been obtained:

(1.) The hydrodynamics and the flow field were measured in a vessel $300 \mathrm{~mm}$ in inner diameter agitated by a Rushton turbine using 2-D Time Resolved Particle Image Velocimetry (2-D TR PIV). The velocity fields were measured in the zone in upward flow to the impeller for three impeller rotation speeds: 300 , 450 and $600 \mathrm{rpm}$, corresponding to a Reynolds number in the range $50000<R e<100000$.

(2.) The dimensionless radial mean velocities were found to be close to zero. These findings correspond to the characteristics of the given zone according to Fořt et al. (1982). This region contains predominantly ascending flow along the vessel axis towards the impeller.

(3.) In accordance with the theory of mixing, the dimensionless mean and fluctuation velocities in the measured directions were found to be constant and independent of the impeller rotational speed. Consequently, the velocity profiles were averaged and were expressed by Chebyshev polynomials of the 1 st order.

(4.) Because the investigated area is relatively far from the impeller and outside the impeller discharge flow, we expected a local state of isotropy defined on the length-scale level corresponding to the integral length scale by equality of the fluctuation velocity components. This expectation was not confirmed. The ratio of the axial $\mathrm{rms}$ fluctuation velocity to the radial component was found to be in the range from 0.523 to 0.768 . This state will affect the determination of the turbulent energy dissipation rate in a given region.

(5.) The axial turbulence intensity was calculated and was found to be in the range from 0.293 to 0.667 , which corresponds to high turbulence intensity. As expected, the highest turbulence intensity was found close to the impeller axis in the ascending flow core.
It was found that the axial turbulence intensity can be statistically taken as constant and independent of the impeller rotational speed. The radial profiles of the axial turbulence intensity were averaged and were expressed by Chebyshev polynomials of the 1st order.

The calculated values for axial turbulence intensity were found to be approximately the same in each horizontal profile. The effect of dimensionless profile height on turbulence intensity was therefore tested by hypothesis testing for each point in the investigated profiles. It was found that the axial turbulence intensity can be characterized using a single formula in the investigated area.

\section{ACKNOWLEDGEMENTS}

This research has been supported by Grant Agency of the Czech Republic project No. 101/12/2274 "Local rate of turbulent energy dissipation in agitated reactors \& bioreactors" and by CTU in Prague project No. SGS14/061/OHK2/1T/12.

\section{REFERENCES}

[1] Drbohlav, J., Fořt, I., Máca, K., Ptáček, J.: Turbulent characteristics of discharge flow from the turbine impeller. Coll. Czechoslov. Chem. Comm., 1978, Vol. 43, pp. 3148-3162

[2] Drbohlav, J., Fořt, I., Krátký, J.: Turbine impeller as a tangential cylindrical jet. Coll. Czechoslov. Chem. Comm., 1978, Vol. 43, pp. 696-712

[3] Obeid, A., Fořt, I., Bertrand, J.: Hydrodynamic characteristics of flow in systems with turbine impellers. Coll. Czechoslov. Chem. Comm., 1983, Vol. 48, pp. 568-577

[4] Fořt, I., Obeid, A., Březina, V.: Flow of liquid in a cylindrical vessel with a turbine impeller and radial baffles. Coll. Czechoslov. Chem. Comm., 1982, Vol. 47, pp. 226-239

[5] Kysela, B., Konfršt, J., Fořt, I., Kotek, M., Chára, Z.: Study of the turbulent flow structure around a standard Rushton impeller. Chem. and Process Eng., 2014, Vol. 35, No. 1, pp. 137-147. DOI: 10.2478/cpe-2014-0010.

[6] Novák, V., Rieger, F., Vavro, K.: Hydraulické pochody v chemickém a potravinářském průmyslu, SNTL, Praha, 1989

[7] Kotek, M., Pešava, V., Kopecký, V., Jašíková, D., Kysela, B.: PIV measurement in a vessel of $\mathrm{D}=0.3 \mathrm{~m}$ agitated by Rushton turbine. Research report for project No. 101/12/2274. Liberec, 2012

[8] Bowerman, B.L., O'Connell, R.T.: Applied statistics: improving business processes. Richard D. Irwin, USA, 1997, ISBN 0-256-19386-X

[9] Rivlin, T.J.: The Chebyshev polynomials. Pure and Applied Mathematics, Willey, New York, 1974

[10] Chebyshev, P.L.: Théorie des mécanismes connus sous le nom parallélogrammes. Mémoires des savants étrangers présentés a l'Académie de Saint-Pétersbourg, 1854, Vol. 7, pp. 539-586 